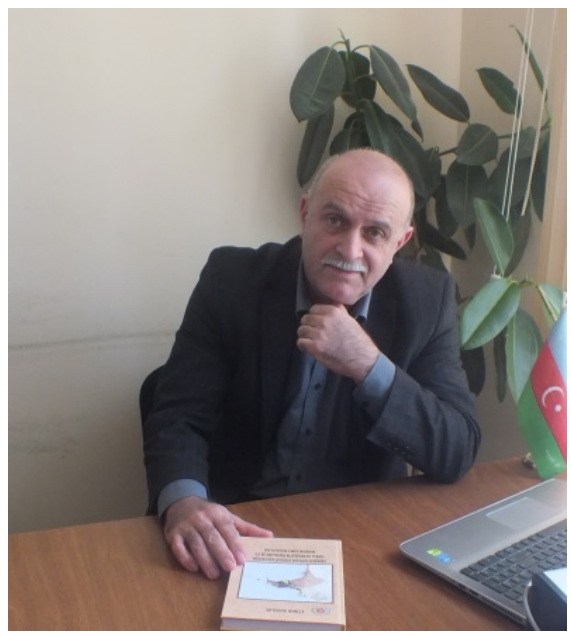

Etibar Sanan Ogly Badalov, Doctor of Philosophy in Geography National Academy of Azerbaijan, Senior Researcher at the Institute of geography Baku, Azerbaijan badalov.1958@mail.ru

DOI 10.31554/978-5-7925-0571-1-2019-2-130-135

\title{
URBANIZATION AND SUBURBANIZATION IN AZERBAIJAN
}

The article analyzes the historical development and formation of urbanization and suburbanization in the urban settlement of Azerbaijan. The process of urbanization and its influence on urban settlement, the problem of development of urban agglomerations are studied. The ways of socio-economic development and transformation of the territorial organization of large and larger urban agglomerations are revealed. The analysis of population growth dynamics in urban agglomerations is carried out. On the basis of the conducted researches recommendations on regulation of urban settlement in Azerbaijan are put forward.

Keywords: urbanization, suburbanization, agglomerations, satellite town, suburbs.

The history of urbanization and suburbanization in Azerbaijan can be divided into 4 stages. The first stage is associated with the development of the oil industry, the intensive growth of which occurred in the 80-90s of the XIX century. In general, over 1880-1913 years the urban population of Azerbaijan more than doubled: from 11 to $24 \%$. The second stage covers the 1930s-1960s, when the Republic began to pursue a policy of industrialization, which resulted in the formation of 38 cities (1933-1967). The number of cities was 54, and the urban population more than doubled: from 24 to $50 \%$. The third stage covers the 1970s-1980s (1968-1991), when 15 set- 
tlements received the status of a city. Eventually, the number of cities increased to 69. The share of urban population in the Republic increased from $50 \%$ to $54.2 \%$, and the population - from 2444.9 to 3858.3 thousands people, therefore, the growth rate was $57.8 \%$. Baku agglomeration, as before, played an important role in the structure of the national economy and was the "locomotive" of urbanization in the Republic. The oil and gas industry played a certain role in the industrialization of the entire Absheron region. It was being developed on the basis of a large city and mining area, genetically representing the whole [Efendiev 2009]. Baku was a monocentric agglomeration and a dense cluster of medium and small satellites was typical for it. According to the number of satellite settlements in 1959, the Baku agglomeration took the second place in the USSR [Cities... 1961]. During the Soviet period, the policy of restraining the growth of Baku was carried out. In 1926-1959 the population of Baku increased by 41.7 $\%$, and its suburbs-by $93.3 \%$. In 1959-1970s - by 32.5 and $51.7 \%$, respectively, in 1970-1989s - by 28.0 and $60.0 \%$ [Badalov 2016]. These indicators prove that the policy of the administrative-command mechanism to limit the growth of Baku in this period was successful, that slowed down the growth rate.

Baku is the main center of urbanization and the industrial core of the country, differing in the territorial concentration of industrial production. The analysis shows that in the Baku urban agglomeration the population increased by 689.5 thousand people from 1970 to 1990 . The trend in the dynamics was formed under the influence of a high pace of natural growth, and in the total growth the share of migration growth decreased to $15 \%$. At the same time, the population growth in Baku itself increased by 338.8 thousand people and in the suburbs-by 350.7 thousand. During this period, major works on housing and cultural construction, territory improvement and greening, development of engineering and transport systems were carried out in Baku. Rapid housing construction and industrial development in the suburban area, as well as in the satellite city of Sumgait, which became an industrial center of petrochemistry and metallurgy, accelerated the process of suburbanization in the Baku agglomeration. Under the conditions of the socialist economic system the growth of cities was rationally regulated in the Republic. During this period, new industrial hubs such as Ganja (Kirovabad)-Dashkesan, Mingechaur-Yevlakh and Shirvan (Ali-Bayramly)Salyan were formed on the basis of the use of local natural resources [Eminov 2005]. They had favorable transport conditions, and there was a concen- 
tration of industry and labor in these hubs. During the evolution process of these cities, their economic functions became more complicated, the sociodemographic composition of the inhabitants changed, the territory of cities and the population increased, small agglomerations were formed.

The fourth stage covers the post-Soviet period, when in the early 1990s in Azerbaijan there was a military aggression by Armenia, as a result of which 12 cities and more than 30 towns were occupied, and more than 1 million people became refugees. The abandonment of planned economy and the transition to a market economy, as well as the rupture of old industrial relations and the war worsened the political and socio-economic situation in the country. During this period, another 9 cities were formed, their number reached 78. In the post-Soviet period (1991-2019) the share of urban population in the Republic decreased to $52.8 \%$, the population growth rate was $36.7 \%$, it increased from 3858.3 to 5273.9 thousand people. The analysis of the dynamics of the urban population revealed that the intensive growth of urbanization occurred in the 1980s and after the 2000s., however, there was also a period of stagnation in the 1990s. In the post-Soviet period from 1991 to 2004, urbanization and suburbanization processes developed at a slow pace, but after 2005 the development of these processes went at a faster pace. The dynamics of the urban population in 2005-2018 increased and amounted to 1061.8 thousand people, including natural growth 666.3 thousand people, or $62.8 \%$, $20 \%$ - due to migration and up to $20 \%$ accounted for new emerging urban settlements.

In the post-Soviet period in the dynamics of urbanization of the regions there was a decrease in the share of urban population in Aran and GanjaGazakh (due to the rapid growth of the rural population of the regions), and a large increase occurred only in Mountainous Shirvan. In 1991-2019, the growth rate of the urban population in all regions ranged from 40 to $60 \%$, the lowest rate was in Ganja-Gazakh (less than $30 \%$ ). The process of development of urban settlement and the dynamics of the number of urban settlements have significant differences in individual urban groups. Large (50100 thousand people) and larger (100-500 thousand people) cities grew the fastest. Small towns developed at a slower pace [Badalov 2014].

There is a hierarchical subordination of cities of different ranks. Its basis is the importance of each city in the entire economic, socio-cultural and administrative life of the Republic. Baku, as the capital of the Republic of Azerbaijan, leads the entire hierarchy of cities not only in terms of population, but also in terms of the diversity and scale of its functions. At the lower 
position there is Ganja-the second center of the Republic, Sumgait-satellite city, Mingechaur-a city of Republican significance, as well as large cities distinguished as the centers of regions. These are Shirvan, Sheki, Guba, Lankaran, Nakhichevan, Yevlakh, etc. Medium-sized and small towns stand out as district centers, but the level of urbanization in them is less developed.

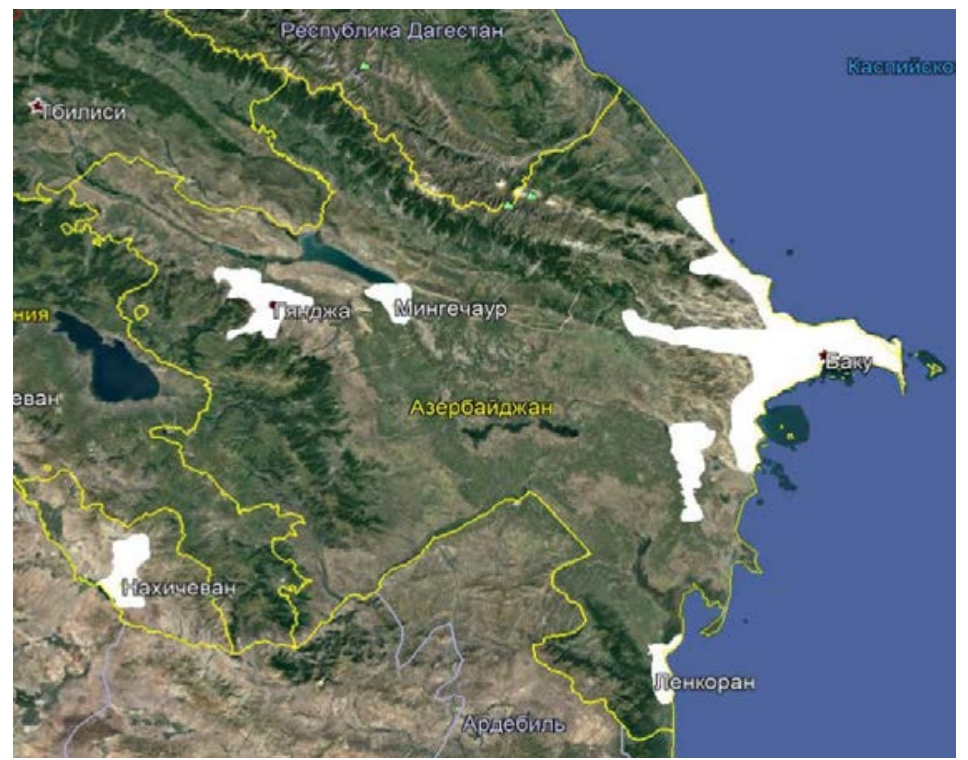

Pic. 1. Agglomeration of Azerbaijan

At the present stage, the Baku agglomeration is characterized by a high level of suburbanization and intensive urban development. During this period, modern industrial parks are being formed around the urban core and in Sumgait , and on the coast of the Peninsula-a resort area. There is also a chaotic development of individual construction, dozens of settlements were built. The agglomeration occupied 2.8 thousand square kilometers, and it included two satellite cities: Sumgait and Khirdalan, 72 settlements and 7 villages, the population was 2.8 million people. The analysis shows that, according to the volume of labor pendulum migrations and the intensity of transport communication, the boundaries of the agglomeration increased. For instance, the increase in transport accessibility to one and a half hour isochronous led to an increase in the territory to 5.0 thousand square kilometers, the number of satellite cities increased to 7 , and the population - to 3.0 
million people. The Suburbanization trends also occur around other major cities. Ganja is the second agglomeration with a territory of more than 1 thousand square kilometers, it has 5 satellite cities, 30 settlements, the population is 480 thousand people. The agglomerations Mingechaur, Shirvan, Lankaran, Nakhichevan are also being formed, there are several cities and towns around them.

To regulate the development of the Baku agglomeration, it is necessary to solve the main problem, which is that more than 600 thousand individual houses do not have registration. There are more than 2 million people living there who do not have a residence permit. They do not belong to the permanent population. Also, more than 500 thousand refugees temporarily live. According to unofficial data, the actual population in the agglomeration is more than 5 million people. This means that the bulk of the country's population is concentrated here. Therefore, despite the construction of new roads and junctions, bridges, underground tunnels, there are transport problems, and suburbanization has led to an increase in pendulum migration and spontaneous territorial sprawl of the city, the deterioration of the ecological situation.

At the present stage of urbanization, large urban agglomerations are the key link of population resettlement. Studies of agglomerations show that their growth and renewal, as well as the enrichment of their functional structure occurred at a slower pace than demographic processes. For the development of urban agglomerations and the transition to a new qualitative state, it is necessary to increase the territories and functions of cities that are the centers of agglomerations. To form their outer zones, it is necessary to transform large villages into settlements.

\section{References and sourses}

Badalov E. S. Osnovniye napraveniya rasvitiya Bakinskoy gorodskoy aglomeratsii [The main directions of development of the Baku urban agglomeration] // Geographiya i prirodniye resursy [Geography and natural resources]. - 2016. Vol. 2. - P. 201-208.

Badalov E. S. Rol planirovki v regulirovanii rasseleniya Bakinskoy aglomeratsii [The role of planning in regulation of settlement of Baku agglomeration] // Prikladniye napravleniya primeneniya sovremennoy geographicheskoy nauki [Applied directions of application of modern geographical science]. - Baku: BSU, 2014. P. 360-365.

Goroda-sputniki [Satellite cities] / ed. by V. G. Davidovich, B.S. Khorev. - M.: State publishing house, 1961. - $195 \mathrm{p}$. 
Eminov Z. N. Naseleniye Azerbadzhana [The population of Azerbaijan]. - Baku: Chirag, 2005. - $560 \mathrm{p}$.

Efendiev V.A. Puti regulirovaniya goroda Baku v edinoy sisteme proizvodstva I rasseleniya Azerbadzhana [The ways of regulation of the Baku city in the unified system of production and settlement of Azerbaijan] //Trudy geographicheskogo obchshestva Azerbadzhana [Works of the Geographical Society Of Azerbaijan]. 2009. - Vol. 14. - P. 128-132. 